\title{
A Few Reflections from Archambault Institution Vincenzo Armeni
}

Wy name is Vincenzo Armeni. I am presently incarcerated at 1 Archambault Medium Security Institution. I am about two-thirds of the way through a 19-year sentence. I have noticed that over the years the system has changed for the worse. For example, I recently applied for a transfer to a minimum-security institution. Although my correctional officer supported my application and the Correctional Manager (CM) sees no reason why I am still here, my Institutional Parole Officer decided that I should remain here until the end of my sentence. The reasons she provides are unfounded. I have been in for well over a decade with no major, nor minor reports. I feel that I should be allowed a gradual release so that I can better prepare myself for my eventual return to the community, which is imminent. The 'cut and paste' system they use to produce reports and assessments for decisions (A4D) must be changed and every prisoner should be reevaluated as per the present. Giving all this power to one person who does a good job of trying to see you as rarely as possible is very unjust and must be corrected immediately.

\section{LIFE SENTENCES}

As for people doing life sentences, I am not a lifer, but I feel they are seriously being treated wrong. I cannot understand why they cannot be given chances to restart a life while they still can. In my opinion a life sentence today is equivalent to a death sentence (Hartman, 2013) and should be changed so that people can start over.

\section{PRISONER PAY}

As for pay I think this point should be looked at again and adjusted with the time. I am earning less today than I was when I began my sentence. While the prices of food have risen with inflation and the food given by the institution has been seriously cut, the quality is at its poorest level ever. As for the people working for CORCAN - I have never and will never work for them. There is no longer any incentive to do so. 


\section{LIVING CONDITIONS}

I am compelled to say that the living conditions (at least here) are disgraceful and jeopardize our health. These issues include:

1. Health care reusing medical supplies. This is very dangerous, unheard of and must be stopped so as to prevent the spread of disease.

2. This place is infested with rodents that come in our cells and sometimes eat our food.

3. Many a guard has told me they would not rinse their mouth after brushing because the water here is so contaminated. Yet it is okay for us to eat, drink, cook and wash in it.

These issues are all in need of redress immediately!

\section{REFERENCES}

Harris, Kathleen (2019) "Audit flags risk of "food related health event" in Canadian prisons", CBC News - June 8. Retrieved from https://www.cbc.ca/news/politics/ prison-food-csc-audit-1.5167222

Hartman, Kenneth (2013) Too Cruel, Not Unusual Enough: An Anthology Published by the Other Death Penalty Project, Lancaster: The Steering Committee Press.

\section{ABOUT THE AUTHOR}

Vincenzo Armeni is imprisoned at Archambault Institution. 